\title{
“STATE-OF-THE-ART" COKING TECHNOLOGIES. CHALLENGING EMISSIONS AT THE SERVICE OF THE ENVIRONMENT: A PRACTICAL BRAZILIAN EXAMPLE*
}

\begin{abstract}
Saving energy and reducing pollution by minimizing emissions are today great challenges in the coking industry worldwide. In order to achieve satisfying results, equipment as well as technology should be continuously improved and updated. The most modern design tools should be adopted to maximize the coke production rate also ensuring the best coke quality. In this scenario, Paul Wurth is realizing the new coke making plant of CSPecem, Ceara - Brazil. These batteries are based on Paul Wurth "jumbo oven concept". This solution incorporates all most modern features and design upgrading, in the aim of an easy and long-lasting operation putting a particular attention to environmental performances: the reduced number of ovens and the low number of pushing per day have the main effect of reducing pollution sources. Finally the paper will highlight Paul Wurth SOPRECO ${ }^{\circledR}$ System, which is foreseen to be installed in CSPecem batteries. SOPRECO ${ }^{\circledR}$, which is capable of controlling the pressure for each individual oven in a coke oven battery, is thus able to reduce volatile emissions through doors, roofs and stand pipes up to $90 \%$. The coke oven gas (COG) produced during the carbonization process is cleaned in a coke oven gas treatment plant to the level stipulated by applying the Best Available Technology (BAT).
\end{abstract}

Keywords: SOPRECO; Coke oven design; Emissions; Coke oven gas treatment.

\author{
Dott. Ing., Head of Coke oven plant department, Paul Wurth Italia S.p.a., Genoa, Italy. \\ Dr., Sales Manager Coke oven plant, Paul Wurth Italia S.p.a., Genoa, Italy. \\ Dipl. Ing, Head of Sales, DMT GmbH \& Co. KG, Essen, Germany. \\ Ing., CSP Project Technical Manager, Paul Wurth Italia S.p.a., Genoa, Italy. \\ Eng. MBA,.Marketing Sales Senior Coordin., Paul Wurth Brazil, Belo Horizonte, MG, Brazil
}

\footnotetext{
* Technical contribution to the $44^{\text {th }}$ Ironmaking and Raw Materials Seminar, $15^{\text {rd }}$ Brazilian Symposium on Iron Ore and $2^{\text {nd }}$ Brazilian Symposium on Agglomeration of Iron Ore, September $15^{\text {th }}$ to $18^{\text {th }}$, 2014, Belo Horizonte, MG, Brazil.
} 


\section{INTRODUCTION}

With the aim to expand steel industry in Ceará State and Brazil, CSP - Companhia Siderúrgica do Pecém is building the most modern steel making plant in South America.

The whole project concerns the construction of a complete, integrated steel plant able to produce in the first phase 3 million tons of steel slabs / year; the doubling of the capacity is foreseen for the second stage.

At the beginning of 2012 POSCO Engineering \& Construction, which is the owner of EPC contract, awarded Paul Wurth with the order for the engineering and key components supply for the complete coke making plant, first coke will be pushed by the end of 2015.

At present the construction at site is proceeding, civil works are almost finished and mechanical / refractory erection has been started for batteries and gas treatment plant.

The project implements state-of-the-art pollution-prevention and energy saving technologies, all components have been developed making use of the most modern design tools and of the huge experience collected by Paul Wurth over the years. CSP coke making plant is mainly composed by following units:

- Two (2) batteries 50 ovens each - jumbo oven type (COB)

- One (1) coal tower

- One (1) wet quenching plant

- One (1) coke wharf

- One (1) gas treatment plant (GTP) made in cooperation with DMT.

The design production capacity is the following:

- Raw Coke - 1,345,755 tpy

- Clean Coke Oven Gas - 87,500 Nm³/h

Here below the general layout of the plant is shown (Figure 1).

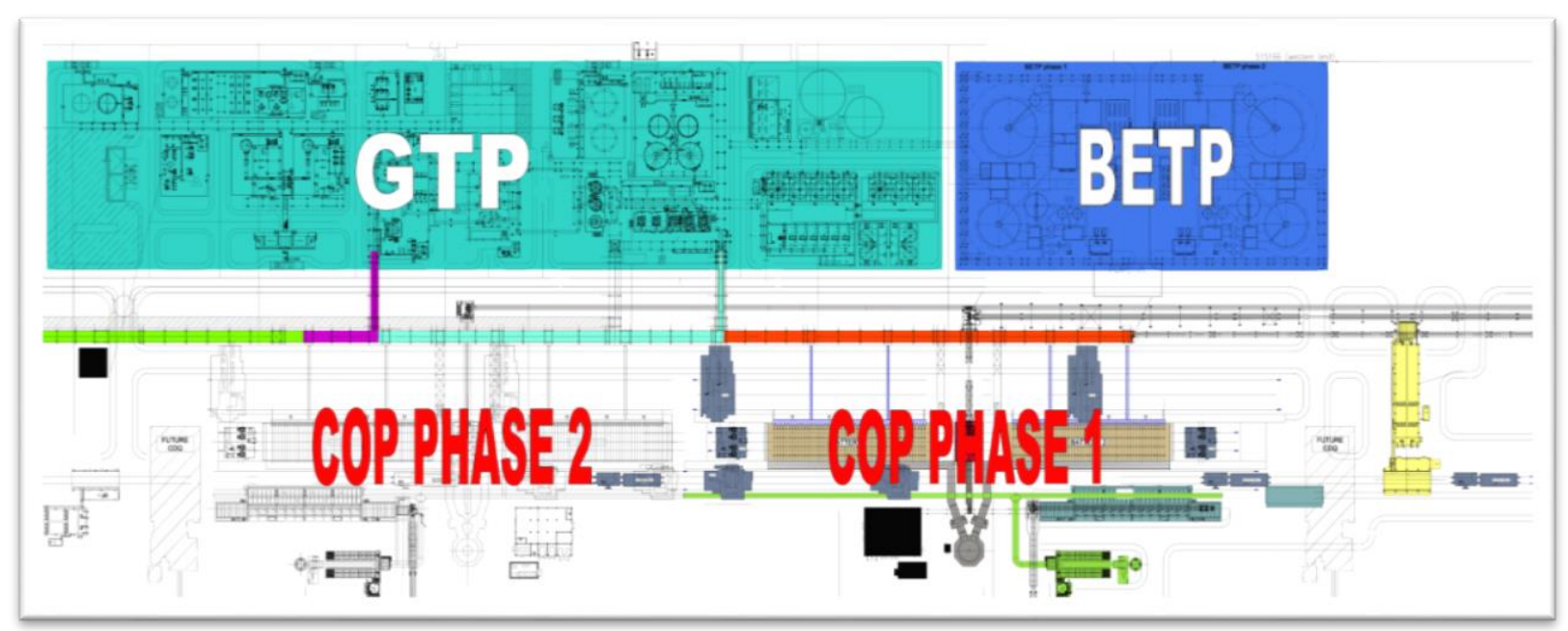

Figure 1. General layout.

* Technical contribution to the $44^{\text {th }}$ Ironmaking and Raw Materials Seminar, $15^{\text {rd }}$ Brazilian Symposium on Iron Ore and $2^{\text {nd }}$ Brazilian Symposium on Agglomeration of Iron Ore, September $15^{\text {th }}$ to $18^{\text {th }}$, 2014, Belo Horizonte, MG, Brazil. 


\section{MAIN FEATURES OF THE PROJECT}

\subsection{Coke Oven Batteries}

CSP batteries are based on PW's jumbo oven concept, they are the first "tall" ovens batteries ever supplied in Brazil, and they've been designed taking into consideration the latest COB technology development:

- Twin flues type

- Compound combustion

- Multi staggered air distribution

- Underjet COG feeding

- Asymmetrical battery configuration: single waste gas channel at coke side air and mixed gas inlet at pusher side

The following table (Table 1) is representing the main figures of the batteries:

Table 1. COB main figures

\begin{tabular}{lc}
\hline Item & Q.ty \\
\hline Ovens number (B1+B2) & $50+50$ \\
\hline Effective length of coking chamber & $17,440[\mathrm{~mm}]$ \\
\hline Full height of coking chamber & $7,600[\mathrm{~mm}]$ \\
\hline Effective height of coking chamber & $7,175[\mathrm{~mm}]$ \\
\hline Average width of coking chamber & $550[\mathrm{~mm}]$ \\
\hline Oven useful volume & $68.82\left[\mathrm{~m}^{3}\right]$ \\
\hline Coal charged per oven (dry) & $51.61[\mathrm{t}]$ \\
\hline Coke pushed per oven & $38.70[\mathrm{t}]$ \\
\hline Charging holes & 4 \\
\hline
\end{tabular}

All dimensions are given in hot conditions.

The useful volume of each coking chamber is about $69 \mathrm{~m}^{3}$; consequently the pushings per day necessary to guaranty the production are much reduced if compared to a conventional oven.

Thanks to the above, the emissions during charging and pushing are dramatically reduced, the ratio of utilization for machines and doors is limited with clear impact to maintenance costs, and the overall efficiency and the expected plant lifetime are significantly increased.

Batteries are designed in order to comply with the severe emission limits imposed by Brazilian regulation, the following main aspects have been considered:

\subsubsection{Distributed visible emissions}

Jumbo Ovens Concept allows a reduced number of ovens, therefore all possible emissions sources such as charging holes, ascension pipe and oven doors are significantly decreased respect to a traditional coke oven battery. In addition to the above, all mentioned items have been designed and produced according to the best available technologies.

\footnotetext{
* Technical contribution to the $44^{\text {th }}$ Ironmaking and Raw Materials Seminar, $15^{\text {rd }}$ Brazilian Symposium on Iron Ore and $2^{\text {nd }}$ Brazilian Symposium on Agglomeration of Iron Ore, September $15^{\text {th }}$ to $18^{\text {th }}$, 2014, Belo Horizonte, MG, Brazil.
} 
Furthermore the application of SOPRECO ${ }^{\circledR}$ system has been included in the project, which is the most reliable technology in terms of single oven pressure control system (please refer to the dedicated chapter of present paper).

\subsubsection{Stack emissions}

In order to ensure the necessary performances in terms of consumptions, environmental impact and product quality, a particular care has been put in the design of the combustion system making use of FAN - Flame Analysis for evaluation of NOx and temperature distribution: a 3D fluid-dynamic model which optimizes the design of the heating walls fluid circulation system.

This tool is decisive to test the effects of the staggered ( 3 levels) combustion air inlet and of waste gases partial recirculation for an even heating and NOx reduction. The simulations are performed by using of FLUENT software which is a CFD calculation tool capable to processes complex geometries.

In addition to the above, the design of oven chambers bricks has been performed in order to guaranty the perfect tightness of the heating walls. This is the first necessary pre-condition to assure the lowest possible dust emissions at the stack.

\subsubsection{Energy Consumption}

Proper choice of insulation materials and correct design of regenerators and combustion system allow a considerable energy saving.

The whole system has been studied and checked making use of proper calculation tools in-house developed by PW.

Here below the main cross section of the battery is shown (Figure 2).

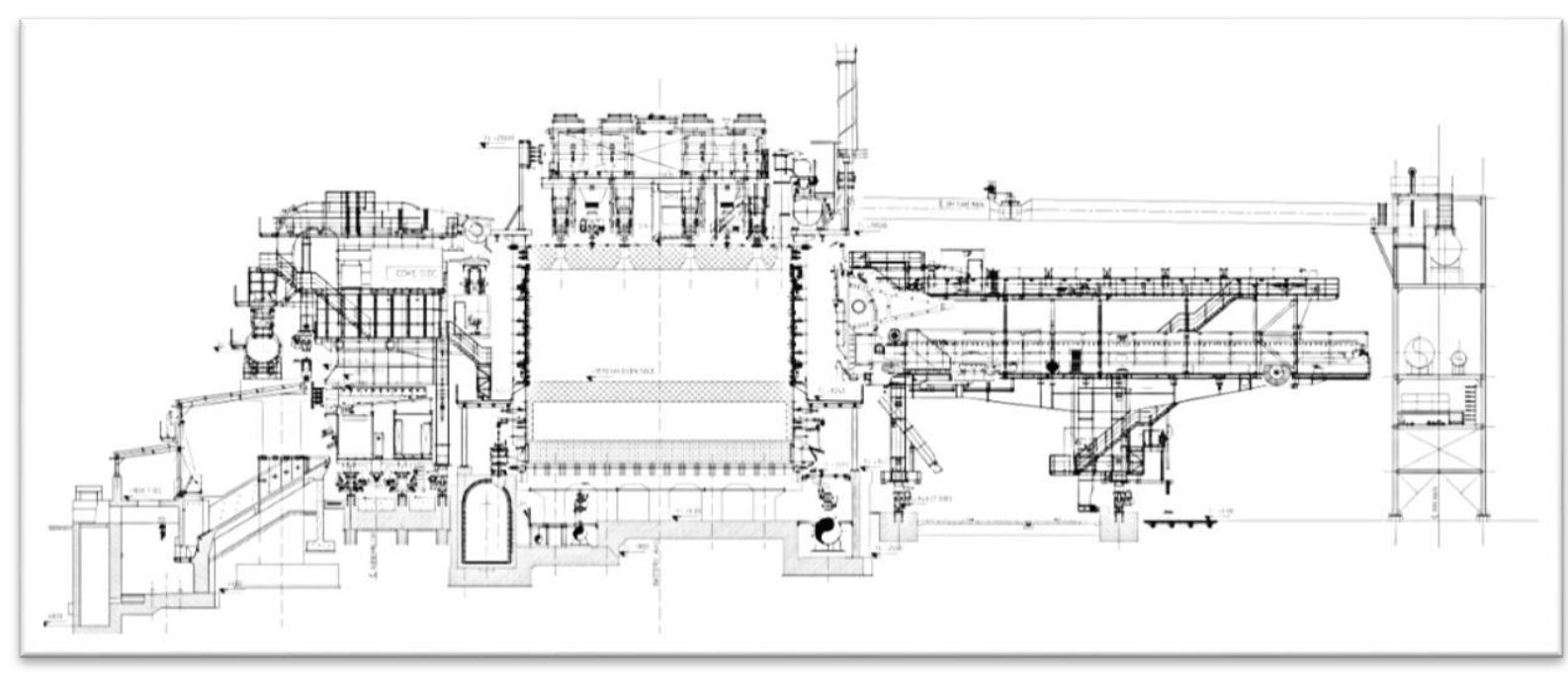

Figure 2. Battery main cross section.

\subsubsection{Technology Highlights: SOPRECO ${ }^{\circledR}$}

\subsubsection{Reduction of coke oven gas emissions}

The need to reduce the high gas emissions at the start of coke distillation and the intake of air through the oven doors at the end of the distillation phase represents an ecological and operating challenge for the owners of coke oven plants. Paul Wurth has therefore developed a system known as SOPRECO ${ }^{\circledR}$ (Single Oven Pressure

\footnotetext{
* Technical contribution to the 44th Ironmaking and Raw Materials Seminar, 15 ${ }^{\text {rd }}$ Brazilian Symposium on Iron Ore and $2^{\text {nd }}$ Brazilian Symposium on Agglomeration of Iron Ore, September $15^{\text {th }}$ to $18^{\text {th }}$, 2014, Belo Horizonte, MG, Brazil.
} 
Control) which is capable of controlling the pressure for each individual oven in a coke oven battery.

The system is based on controlling the oven pressure via a special spherical valve installed between the isolating valve and the goose neck pipe. The valve is driven by a pneumatic actuator under PLC control and it is flushed continuously with low pressure ammonia liquor.

The suction effect in the first phase of coking is optimized with a reduction of the emissions through poorly sealed doors caused by excess oven pressure. During the coking process, the pressure control guarantees a minimum positive pressure at the base of the oven, also in the end phase, thus preventing air intake into the ovens.

A reduction of volatile emissions through doors, roofs and stand pipes can be achieved by the process.

SOPRECO ${ }^{\circledR}$ furthermore allows the charging procedure to take place without injection of high-pressure ammonia liquor. The system has proven its effectiveness in batteries with both top charging and stamp charging in more than 400 installations worldwide.

\subsubsection{Supracok level 2 system}

Nowadays, top level performances and high flexibility are required for plant operation in order to fulfill today's market challenges and minimize environmental impact.

Moreover Level 2 Systems have become an essential part in coke oven plants operation.

SUPRACOK integrates mathematical models and supervision functions, aiming at: thermal control of the battery, monitoring of the coking process, scheduling of charging / pushing operations, on the basis of production requirements, actual process data, and also taking into account anomalous conditions such as production stops, delays and maintenance of single ovens.

Scheduling algorithm is used, as well, in discrete event simulation giving the possibility to highlight the possible bottlenecks of thermal groups.

The interaction between operators and SUPRACOK is carried out by means of a comprehensive and user-friendly Human-Machine Interface developed with state-ofart software technologies.

SUPRACOK is highly flexible and can be easily customized in accordance to actual Customer requirements.

SUPRACOK provides the coke oven plant operators with a powerful, accurate, easyto-use support tool, which can be successfully used to improve operation performances and achieve the following benefits:

- Higher quality of produced coke

- Reduction of gas consumption

- Improvement of operation stability and safety

- Easier achievement of environmental requirements

- Increase of battery life time

- Timely and comprehensive information to the operators.

For the CSP batteries PW has integrated in SUPRACOK the supervision of SOPRECO system including all the features normally included in Level 1 supervision in addition to new control features.

Here below a simplified sketch of the thermal model allowing the optimization of the thermal flow rate to the battery (Figure 3 ).

\footnotetext{
* Technical contribution to the $44^{\text {th }}$ Ironmaking and Raw Materials Seminar, $15^{\text {rd }}$ Brazilian Symposium on Iron Ore and $2^{\text {nd }}$ Brazilian Symposium on Agglomeration of Iron Ore, September $15^{\text {th }}$ to $18^{\text {th }}$, 2014, Belo Horizonte, MG, Brazil.
} 


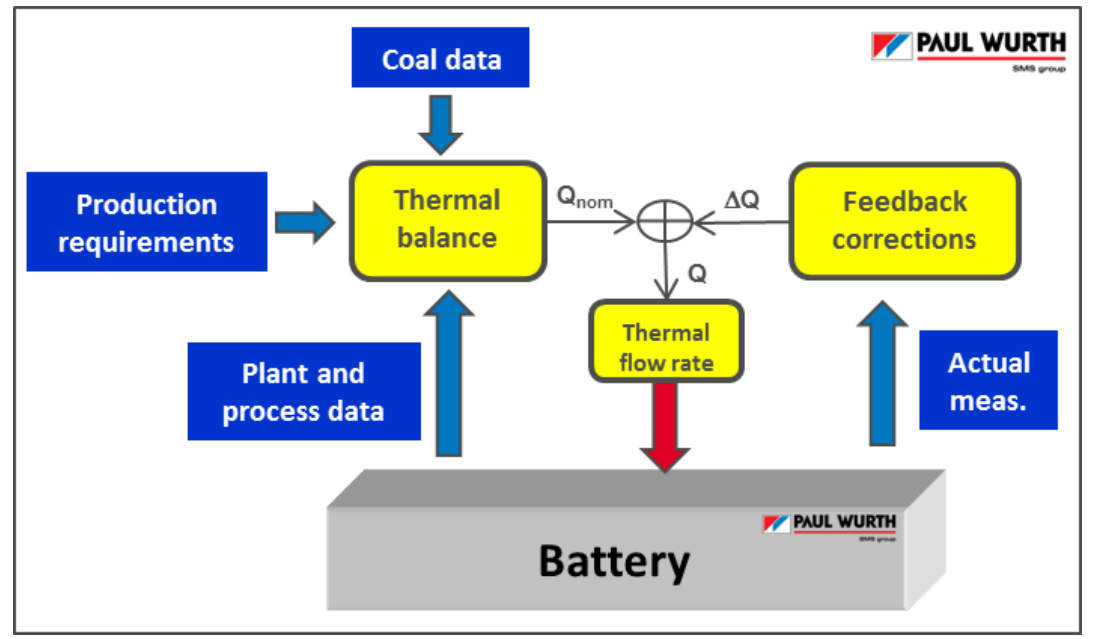

Figure 3. Thermal model

\subsection{Coal Tower}

Coal tower arrangement has been developed to fit with coal throughput exigencies and to accommodate the main coke oven battery facilities such as:

- Control room

- Electrical room

- PLC room

- Hydraulic rooms for both batteries

All floors are served by a dedicated elevator able also to carry the required spare parts and consumables.

Coal distribution system arranged on the tower top floor is composed by a set of fixed reversible conveyors; the whole area is closed and covered by a metallic shelter.

To assure a "dust free" environment the system is served by a dedicated de-dusting unit (local bag filter and fan).

Charging cars filling is performed by two independent bins rows, the sliding gates are directly actuated by the machines.

A proper automatic anti-bridging system grants the correct material flow and the absence of clogging.

In the same area is arranged the lid luting system, with the aim to prepare the luting material to be carried and applied by the charging car itself.

Here below the main sections of the coal tower are shown (Figure 4).

* Technical contribution to the 44 $4^{\text {th }}$ Ironmaking and Raw Materials Seminar, $15^{\text {rd }}$ Brazilian Symposium on Iron Ore and $2^{\text {nd }}$ Brazilian Symposium on Agglomeration of Iron Ore, September $15^{\text {th }}$ to $18^{\text {th }}$, 2014, Belo Horizonte, MG, Brazil. 

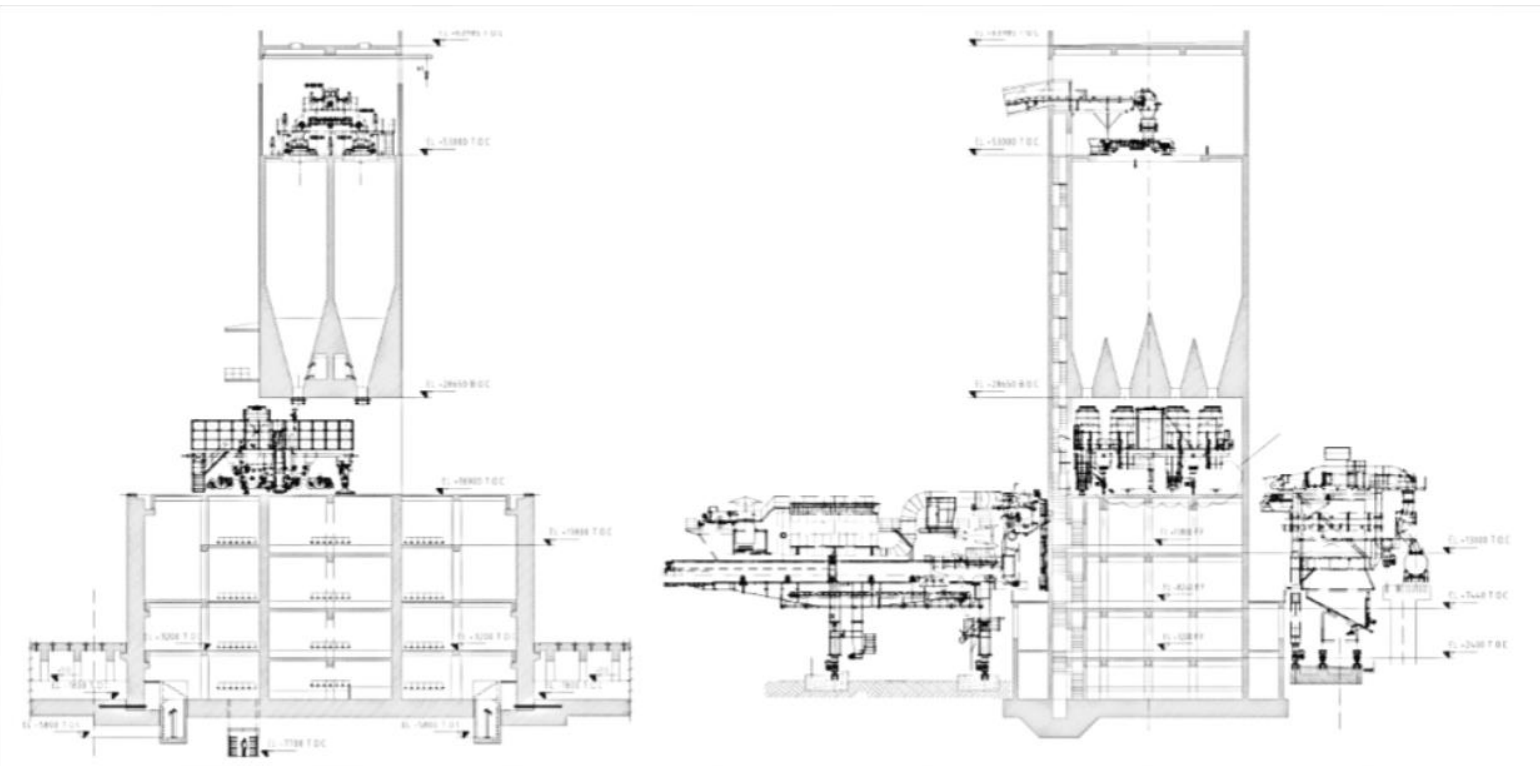

Figure 4. Coal tower main sections.

\subsection{Wet Quenching}

For CSP project the guarantee figure relevant to quenching tower dust emission is $\leq 50 \mathrm{~g} /$ ton coke.

The quenching system designed for CSP is PWIT LOw MOisture type.

The quenching tower is an RCC construction $47 \mathrm{~m}$ height, with a wide steam outlet area, in order to get low outlet speed for steam and therefore a low dust output. The tower is lined in the internal part with anti-acid clinkers bricks.

The coke is quenched by laminar flow of water coming from two tanks with capacity of $90 \mathrm{~m}^{3}$ each.

Quenching water is distributed on the coke surface thanks to horizontal pipes located above the car quenching position.

In order to condensate the water steam generated during this process and to capture the coke particles contained in the steam, the quenching tower is equipped with:

- Steam washing system

- Upper dust capture system

The settling basin is equipped with grab crane for coke dust removal. Coke boxes are provided for removal of the remained dust in the water.

Dedicated pumps take the cooling water, coming from the settling basin, up to the tanks in the quenching tower. Because of this water partially evaporates during coke cooling, there is a level switch in the settling basin that opens a valve installed in the industrial water line for the refilling.

Here below the main section of the quenching tower is shown (Figure 5).

* Technical contribution to the 44 Ironmaking and Raw Materials Seminar, $15^{\text {td }}$ Brazilian Symposium on Iron Ore and $2^{\text {nd }}$ Brazilian Symposium on Agglomeration of Iron Ore, September $15^{\text {th }}$ to $18^{\text {th }}$, 2014, Belo Horizonte, MG, Brazil. 


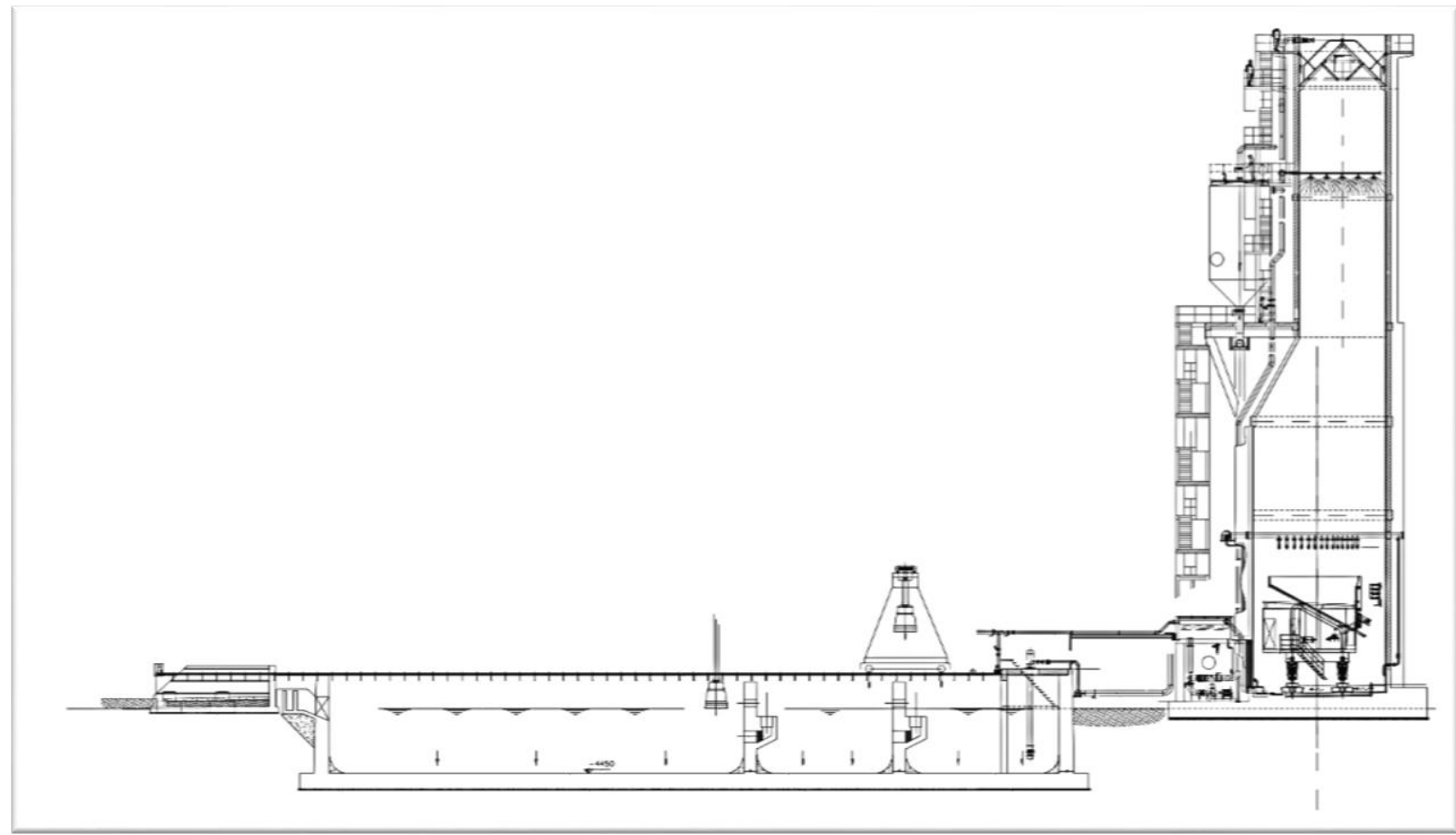

Figure 5. Quenching tower and settling basin main section.

\subsection{Coke Wharf}

The quenched coke is transported by a quenching car to the coke wharf placed in front of battery 2 .

The whole wharf is closed by a metallic shelter in order reducing dust emissions and to protect operators and coke against rainfall.

An automatic plough feeder is arranged at the bottom of the wharf, coke level detection in the ramp is carried out by radar sensors. The whole system is designed to work in automatic mode.

Finally the coke is conveyed to the treatment (crushers and screens) and then to storages and Blast Furnace.

Belt conveyors are protected by hot spot detection and automatic water spray system.

Here below the main section of the coke wharf is shown (Figure 6).

* Technical contribution to the $44^{\text {th }}$ Ironmaking and Raw Materials Seminar, $15^{\text {rd }}$ Brazilian Symposium on Iron Ore and $2^{\text {nd }}$ Brazilian Symposium on Agglomeration of Iron Ore, September $15^{\text {th }}$ to $18^{\text {th }}$, 2014, Belo Horizonte, MG, Brazil. 


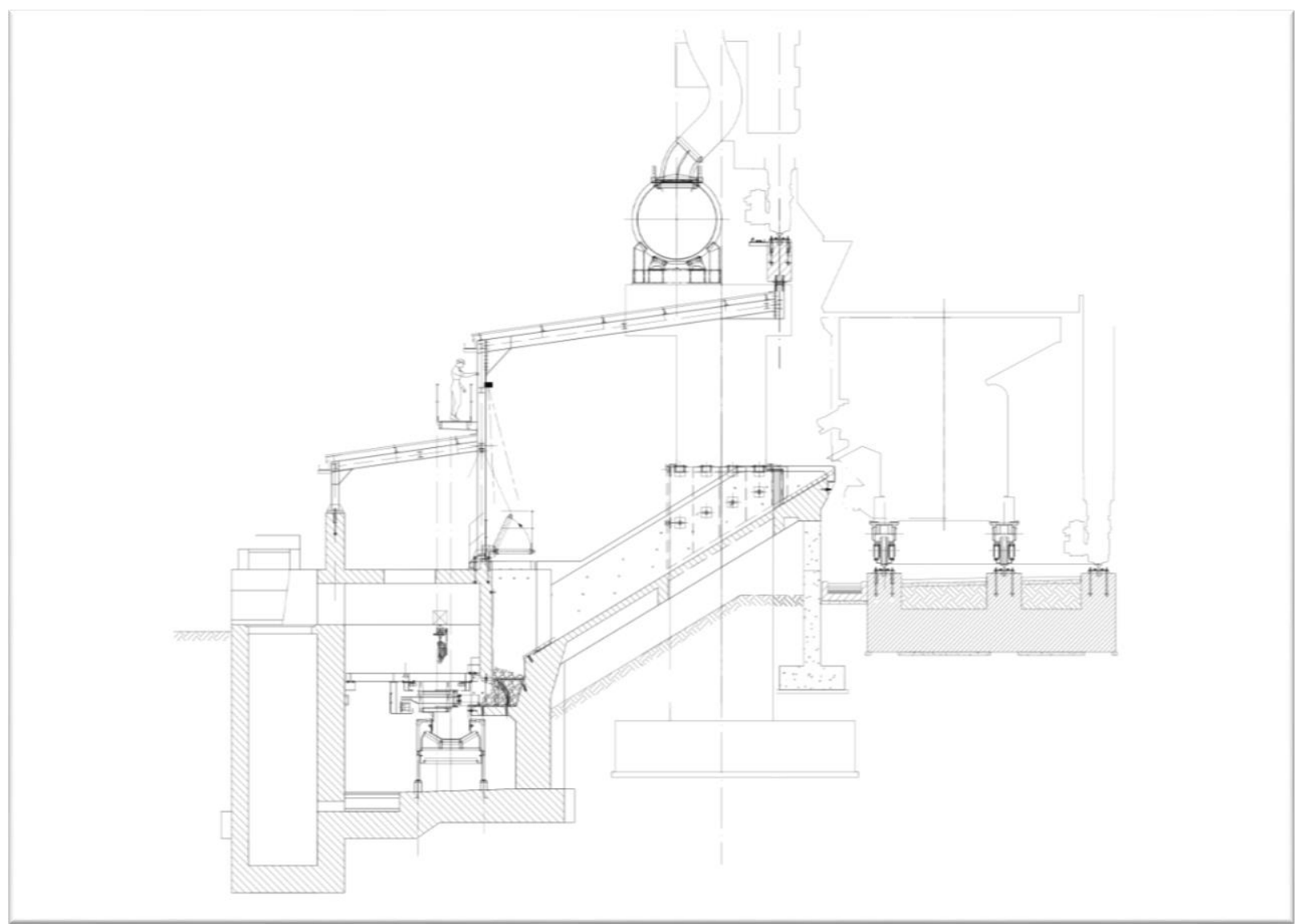

Figure 6. Coke wharf main section

\subsection{Gas Treatment Plant (GTP)}

CSP Gas Treatment plant is a complete byproduct plant able to treat $87,500 \mathrm{Nm} 3 / \mathrm{h}$ of COG.

The GTP is the implementation of the close partnership between Paul Wurth and DMT, the German leading company in Coke Oven Gas Treatment Plants.

The gas treatment plant is composed of the following units:

- Primary gas cooler (PGC)

- Electrostatic tar precipitator (ETP)

- Gas exhauster (GE)

- $\mathrm{H} 2 \mathrm{~S} / \mathrm{NH} 3$ scrubbing

- BTX / naphthalene scrubbing

- Tar decanting

- Tar storage

- Gravel filter

- NH3 distillation plant

- BTX recovery

- Claus plant

Here below the main process flow diagram of the gas treatment plant is shown (Figure 7).

* Technical contribution to the $44^{\text {th }}$ Ironmaking and Raw Materials Seminar, $15^{\text {rd }}$ Brazilian Symposium on Iron Ore and $2^{\text {nd }}$ Brazilian Symposium on Agglomeration of Iron Ore, September $15^{\text {th }}$ to $18^{\text {th }}$, 2014, Belo Horizonte, MG, Brazil. 


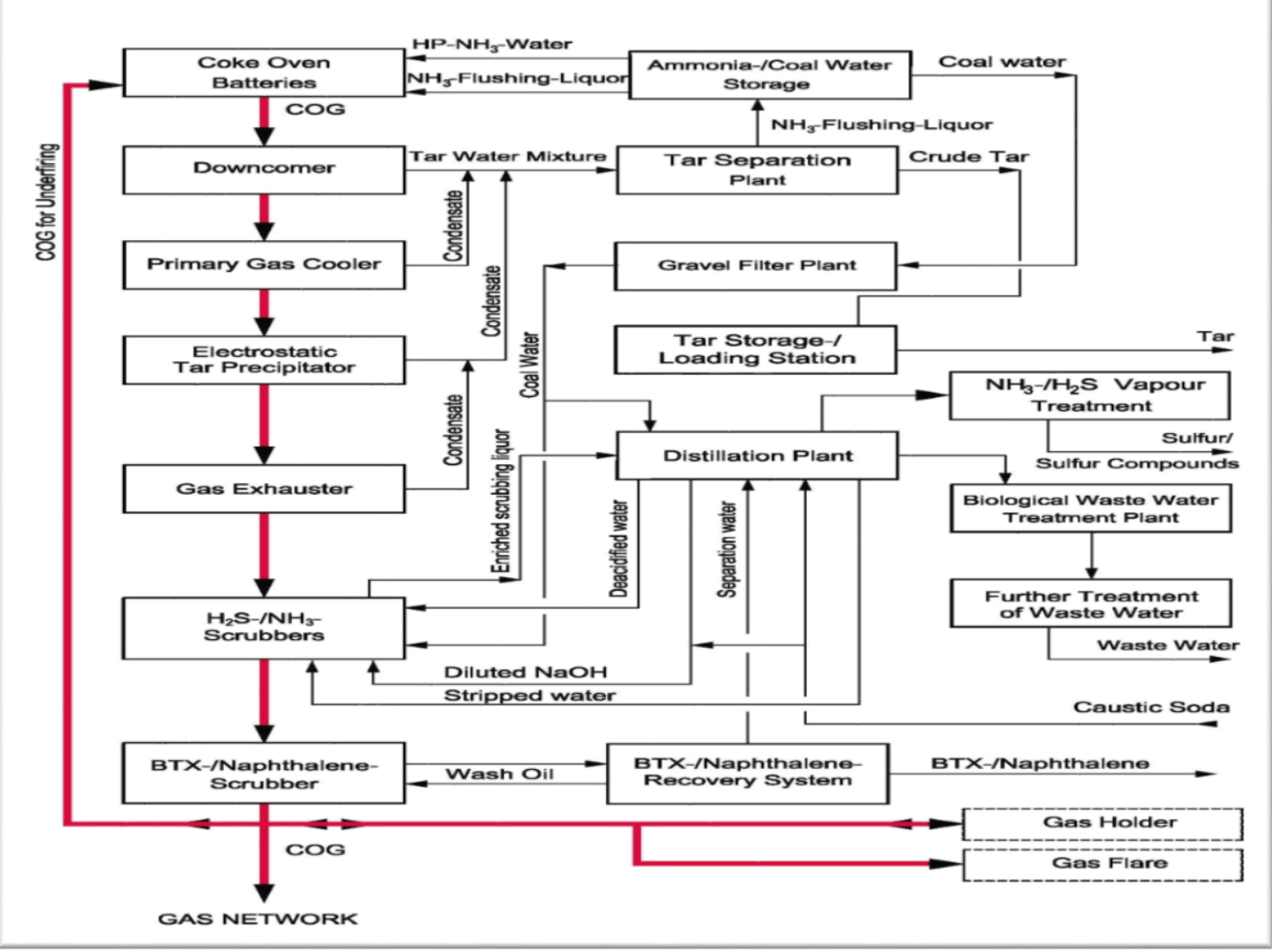

7. GTP main flow diagram

The complete plant has been 3D modelled and a complete overview is reported here below (Figure 8).

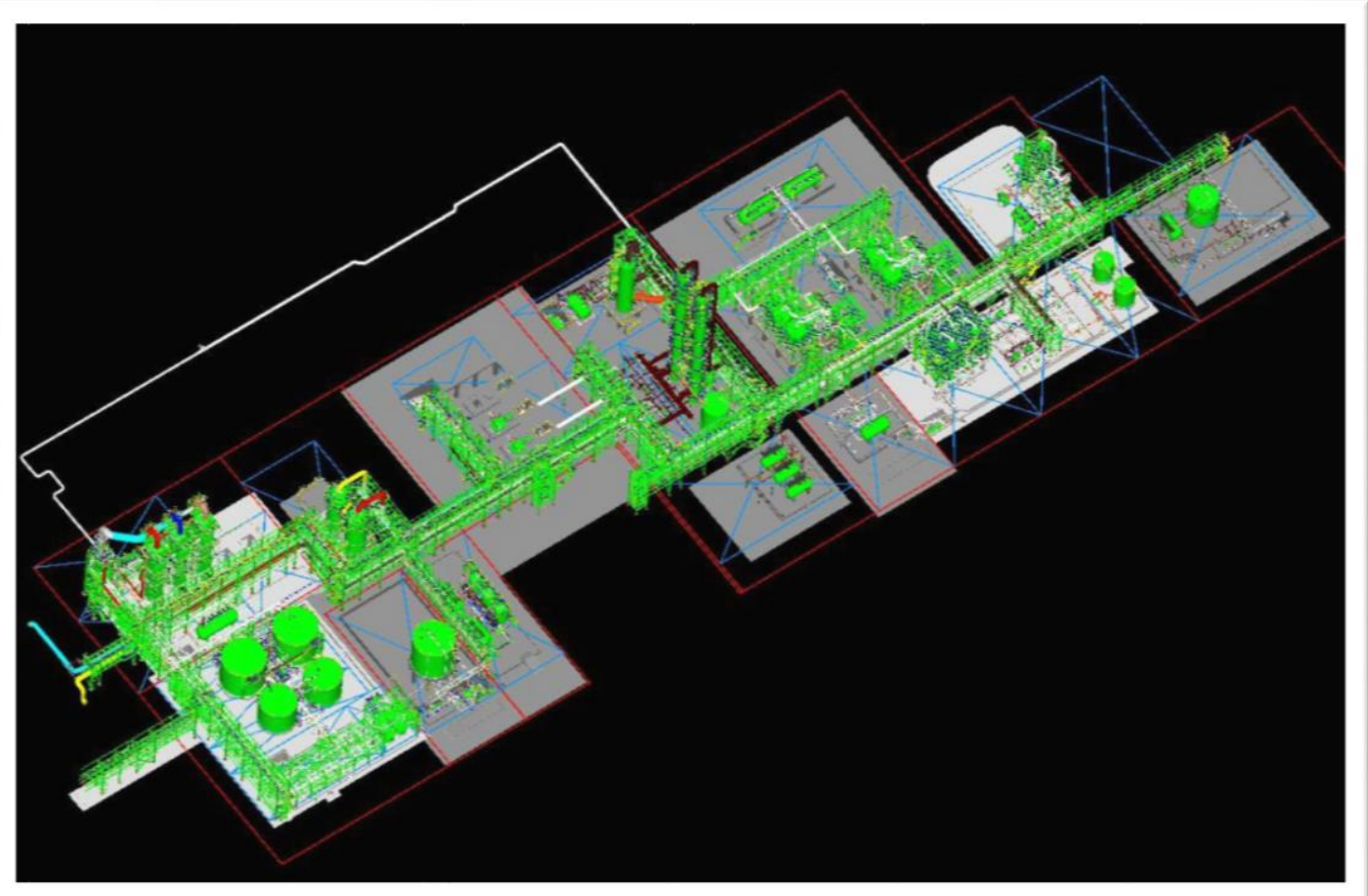

Figure 8. CSP Gas treatment plant - 3D View.

\footnotetext{
* Technical contribution to the $44^{\text {th }}$ Ironmaking and Raw Materials Seminar, $15^{\text {rd }}$ Brazilian Symposium on Iron Ore and $2^{\text {nd }}$ Brazilian Symposium on Agglomeration of Iron Ore, September $15^{\text {th }}$ to $18^{\text {th }}$, 2014, Belo Horizonte, MG, Brazil.
} 
Crude coke oven gas coming from coke oven batteries, including the loaded flushing ammonia liquor is taken over from crude gas mains and enters GTP. Leaving downcomer, where the separation with ammonia flushing liquor is performed, COG is directed to PGC. Here COG is cooled down within two indirect cooling stages using both cooling and chilled water. Using continuously operated flushing system with tar emulsion, ad hoc prepared, for cleaning purpose the operation time is optimized.

Tar and ammonia water mixture leaving the down-comer is directed to the static tar separation plant. From tar separation plant, flushing liquor is returned to the collecting main for flushing COG coming from $\mathrm{COB}$, while coal water is discharged via tank to gravel filter for final tar removal. Leaving the tar separation plant the crude tar, as product, is led via storage and loading station to further disposal. After collecting and preparing within the tar separation plant, by tar solid decanters, solid particles are finally discharged into battery feed coal.

Coming from PGC, cooled COG flows through electrostatic tar precipitator (ETP) for reducing tar content upstream gas exhausters. The cooled and tar reduced COG passes the gas exhausters driven by electrical motors. The required performed and suction pressure of the gas exhausters have to be considered for the pressure difference of the entire gas treatment plant, beginning from coke oven batteries down to the inlet of COG network.

After leaving gas exhausters COG passes a scrubber system with integrated final and internal cooling stages for reducing H2S / NH3 components. By these cooling stages, operated indirectly with chilled water, the reached temperature level ensures the required performance value of scrubbing system. The scrubbing liquor for $\mathrm{H} 2 \mathrm{~S} / \mathrm{NH} 3$ removal consists of stripped and de-acidified water supplied by distillation plant.

As final gas cleaning stage a BTX- / naphthalene scrubber is applied. In order to reduce the $\mathrm{BTX}$ - and naphthalene content the COG coming from H2S- / NH3scubbers is scrubbed by special tar based wash oil. For the regeneration of the wash oil and the production of crude BTX as product a stripping system is provided.

In order to strip the H2S- and free ammonia-compounds from the enriched scrubbing liquor coming from the $\mathrm{H} 2 \mathrm{~S}$ and $\mathrm{NH} 3$-scrubbers, a distillation plant consisting of deacidifiers (DS) and ammonia strippers (AS) is provided with the capability to handle the entire scrubbing liquor. The excess coal water, leaving the gravel filter plant, is stripped under the presence of caustic soda $(\mathrm{NaOH})$ in a fixed ammonia still column section to remove the fixed ammonia compounds. The surplus outlet stream is led to the biological effluent treatment plant (BETP).

The vapours leaving the distillation plant, mainly consisting of $\mathrm{H} 2 \mathrm{~S}, \mathrm{NH} 3, \mathrm{HCN}, \mathrm{CO} 2$ and hydrocarbons, will be treated in a combined NH3 cracking- / elementary sulphur plant (Claus Plant). In this process the NH3- / HCN components are cracked while the H2S content is converted to liquid sulphur. The tail gas flow of the Claus Plants is returned to the crude gas mains upstream the primary gas coolers.

In order to avoid emissions and for safety reasons, various tanks, vessels and specific process equipment are connected to a nitrogen respiration system. The installation of a pressure control unit the nitrogen feeder is connected to the equipment which is subject to N2-purging. From connected equipment N2 is directed back to a common return line, connected to the COG suction main downstream of the ETP`s. By the installation of special seal pots it can be avoided that tanks and vessels will be over-pressurized or are exposed to strong vacuum conditions.

Table 2 shows cleaned COG pollutant composition after treatment:

\footnotetext{
* Technical contribution to the $44^{\text {th }}$ Ironmaking and Raw Materials Seminar, $15^{\text {rd }}$ Brazilian Symposium on Iron Ore and $2^{\text {nd }}$ Brazilian Symposium on Agglomeration of Iron Ore, September $15^{\text {th }}$ to $18^{\text {th }}$, 2014, Belo Horizonte, MG, Brazil.
} 
Table 2. COG pollutants

\begin{tabular}{ccc}
\hline Tar & $g / N m 3$ & $<0,02$ \\
\hline H2S & $g / N m 3$ & $<0,5$ \\
\hline NH3 & g/Nm3 & $<0,04$ \\
\hline BTX & g/Nm3 & $<5$ \\
\hline
\end{tabular}

\section{CONCLUSION}

Thanks to the application of innovative calculation methods and to the huge experience achieved, PW is able to optimize coke making plants design, overcoming known problematic issues, thus giving constancy to operational performances and, above all, achieving the most stringent environmental parameters which fully satisfy international standards in force.

Moreover, a continuous project monitoring and management give to the Customer the guaranty of specification and time schedule respect; being those the key aspects to a successful project.

CSPecem will be the example for the modern way of coke making.

\section{BIBLIOGAPHY}

1 All documentation published in this paper, are internal documents of Paul Wurth Italia and DMT GmbH \& CO. KG.

* Technical contribution to the 44 $4^{\text {th }}$ Ironmaking and Raw Materials Seminar, $15^{\text {rd }}$ Brazilian Symposium on Iron Ore and $2^{\text {nd }}$ Brazilian Symposium on Agglomeration of Iron Ore, September $15^{\text {th }}$ to $18^{\text {th }}$, 2014, Belo Horizonte, MG, Brazil. 